I Pontifícia Universidade Católica do Rio de Janeiro (PUC-Rio), Departamento de Ciências Sociais, Rio de Janeiro, RJ, Brasil burgos@puc-rio.br https://orcid.org/oooo-oooI-9766-8848

I I Pontifícia Universidade Católica do Rio de Janeiro (PUC-Rio), Departamento de Ciências Sociais, Rio de Janeiro, RJ, Brasil Marcelo Tadeu Baumann Burgos' caiquebellato@hotmail.com Caíque Cunha Bellato" https://orcid.org/oooo-000I-9984-5190

\title{
GERENCIALISMO E PÓS-GERENCIALISMO: EM BUSCA DE UMA NOVA IMAGINAÇÃO PARA AS POLÍTICAS EDUCACIONAIS NO BRASIL
}

\section{INTRODUÇÃo}

A estrada que nos conduziu ao universo de questões deste artigo foi a da pesquisa sobre a relação entre educação escolar e democracia, bem como a da compreensão de que essa agenda, onde quer que ela se coloque, necessariamente interpela a relação entre Estado, sociedade e mercado. Do ponto de vista mais propriamente sociológico, tal agenda reclama levar a sério a discussão sobre o destino da escola enquanto instituição e o modo como, no caso brasileiro, ela ocupa lugar central no trabalho de formação das novas gerações, muito especialmente de crianças das classes populares.

O fato de o debate atual sobre educação estar fortemente dominado por enfrentamentos puramente ideológicos, quando ainda enfrentamos graves problemas de acesso à aprendizagem, é um forte sintoma daquilo que neste artigo estamos caracterizando como um vazio de imaginação, que se teria seguido ao esgotamento do gerencialismo enquanto referencial conceitual e político que dava sentido às agendas reformistas implementadas nas últimas décadas. Por isso, a fim de contribuir para o desenvolvimento de uma imaginação capaz de sustentar o aprofundamento dos importantes avanços conquistados no país na área de educação, propomos, neste artigo, uma nova constelação de premissas conceituais que conformam aquilo que, na falta de melhor termo, denominamos pós-gerencialismo.

A questão da relação entre o gerencialismo e a reforma educacional nos chegou como um desdobramento analítico que, a certa altura, nos pareceu 
incontornável, já que ficava evidente a necessidade de se enfrentar o que se afigurava como um dilema entre, de um lado, a tomada de medidas de gestão para se tentar fazer valer o direito à aprendizagem, e, de outro, o compromisso da escola com uma cultura democrática, aberta à plena participação da comunidade escolar, a começar pelos próprios estudantes. Foi nesse percurso que "topamos" com uma literatura internacional ainda pouco difundida entre nós e que, em seu conjunto, enfrenta exatamente o mesmo dilema. Com a ressalva de que, no seu caso, esse dilema foi originalmente colocado pela percepção do esgotamento do modelo burocrático do Welfare State para assegurar os direitos conquistados em contextos de socialdemocracia.

As políticas públicas educacionais implementadas no Brasil a partir dos anos I990, tanto pelo governo federal quanto por estados e municípios, têm sido fortemente atravessadas pelo debate em torno da sua maior ou menor porosidade à influência do gerencialismo. Nesse sentido, pode-se mesmo afirmar que, mais do que um paradigma no sentido conceitual, o gerencialismo se torna no país uma categoria política. ${ }^{\mathrm{I}}$

Na sua origem, o gerencialismo remete à reação conservadora iniciada na Inglaterra contra o modelo burocrático do Welfare State. De modo muito sintético, pode-se entender o gerencialismo como uma doutrina de reforma do Estado inspirada em princípios importados do mercado e que tem como principais características o planejamento e a elaboração de políticas com ênfase em metas de desempenho para nortear o funcionamento do setor público. No Brasil, a entrada do gerencialismo ganha força, sobretudo a partir do período de Fernando Henrique Cardoso (I994-2002), servindo como um modelo de gestão pública para a reforma do Estado, com vistas a torná-lo mais eficiente e voltado para os interesses dos cidadãos (Paes de Paula, 2005).

Apesar disso, nem na Inglaterra e nem no Brasil o gerencialismo chega a romper com o modelo burocrático que pretendia superar, tendo muita dificuldade de se afastar da concepção tecnocrática tão criticada por aqueles que reclamavam mais participação nos processos decisórios sobre questões de interesse público. Essa marca de origem está presente, de certo modo, na forma como o gerencialismo se converte em categoria política no Brasil. Importado como chave teórica para informar o sentido da reforma administrativa, o gerencialismo logo se torna uma influente doutrina para a administração pública do país, estimulando e moldando a imaginação reformista nos mais diversos setores da vida brasileira. E aqui, com ainda mais ênfase do que em seu contexto de origem, o gerencialismo fundamentará a ação de elites políticas reformistas animadas pelo projeto de modernização dos mais diferentes serviços públicos. Na área da educação, essa presença se faz especialmente relevante e, como argumenta Dusi (2017), influencia grande parte das políticas educacionais implementadas pelos estados brasileiros entre finais dos anos ig9o e o início da década de 20 io. 
Além de orientar políticas reformistas de muitos estados da federação, o gerencialismo também define boa parte das controvérsias políticas e doutrinárias travadas no país nesse mesmo período acerca da administração pública. De especial relevância, nesse caso, é a questão da maior ou menor abertura à participação da sociedade e dos "burocratas de nível de rua" no processo decisório e na implementação das políticas. ${ }^{2}$ Bem como a discussão acerca dos mecanismos de controle, responsabilização e prestação de contas em face da efetividade, eficácia e eficiência de uma determinada política.

Como demonstra Paes de Paula (2005), a influência gerencialista polariza o debate público no Brasil desde os anos I990, e, segundo a autora, já no primeiro governo Lula, do Partido dos Trabalhadores (2003-2006), ganha corpo uma antinomia entre dois modelos, aqui entendidos como tipos ideais. De um lado, o modelo gerencialista, em sua busca por eficiência e eficácia, mas ainda preso a um viés tecnocrático, e, de outro, um modelo que, em nome da valorização da cidadania e sem abandonar explicitamente o compromisso com a eficiência e a eficácia, pretende investir na "participação no nível das instituições", enfatizando "a elaboração de estruturas e canais que viabilizem a participação popular" (Paes de Paula, 2005: 4I).

Apesar de reconhecer a continuidade das práticas gerencialistas no governo petista, Paes de Paula chama atenção para o fato de que o modelo de "administração pública societal" permanece como tendência latente, e para isso concorre o fato de a Constituição de I 988 ter acolhido anseios - que, em seu entendimento, teriam sido gestados desde os anos I960 - de se assegurar maior participação popular na gestão pública.

De fato, na área da educação, a emergência do gerencialismo significou um duro combate à aposta na valorização da participação como dimensão fundamental do controle social da gestão escolar, e boa parte das tensões e contradições que acompanham as reformas educacionais desde os anos I990 tem a ver com esse enfrentamento entre as duas modelagens. Daí a sugestão, presente neste artigo, de que a tendência que estamos caracterizando como pós-gerencialista aponta, de algum modo, para uma certa convergência desses dois modelos. ${ }^{3}$

Nesse sentido, nossa proposta é a de que a noção de pós-gerencialismo seja reservada para caracterizar um processo que, na verdade, não pode ser tratado como antítese do gerencialismo, mas sim como uma tendência que ressignifica diversos aspectos daquele modelo, ao mesmo tempo em que incorpora a dimensão da participação sob nova perspectiva, ao emprestar maior ênfase à cultura profissional como dimensão fundamental para se assegurar a qualidade do serviço público.

Para desenvolver nosso argumento, adotamos como fonte de inspiração uma literatura internacional, boa parte dela anglo-saxônica, e tomamos como referência três dimensões que, segundo nosso entendimento, sintetizam bem 
os pontos cardeais da ultrapassagem do gerencialismo. Em primeiro lugar, a dimensão da discussão em torno da perspectiva top-down e bottom-up. Essas duas categorias têm sido utilizadas para comparar diferentes desenhos de políticas públicas, sendo a primeira cara a políticas de reforma mais verticais, e a segunda, a políticas concebidas de modo mais horizontal. Como veremos, mais do que propor uma inversão ou a exclusão de uma das duas perspectivas, a tendência pós-gerencialista procura definir formas novas de equilíbrio entre elas. Disso se segue uma segunda dimensão, que remete à valorização da cultura profissional, e ao desenvolvimento de novas formas de cooperação. A tendência pós-gerencialista empresta especial atenção às formas coletivas de organização, associadas a uma ética de responsabilidade com a produção de resultados escolares. Por fim, uma terceira dimensão pode ser caracterizada como uma nova valorização da figura da liderança, ou melhor, de um sistema capaz de produzir lideranças em diferentes níveis do sistema escolar. A aposta no líder necessariamente remete aos atributos pessoais, por isso, a fim de evitar os evidentes limites do personalismo, o modelo pós-gerencialista procura corrigi-lo por meio de uma concepção que valoriza o exercício da liderança como um elemento que é, ao mesmo tempo, pessoal e sistêmico.

Antes de apresentarmos de modo mais aprofundado essas três dimensões, importa fazer algumas rápidas considerações sobre a recepção do gerencialismo no Brasil e de como ele estaria se esgotando como fonte de imaginação, deixando-nos, momentaneamente, desarmados para pensar a reforma educacional.

\section{O GERENCIALISMO NO BRASIL}

A chegada do gerencialismo no Brasil é um marco importante da reforma do Estado brasileiro realizada durante o período FHC. Sua recepção foi fartamente associada ao que se anunciava como "o fim da Era Vargas", isto é, a um modelo de articulação entre Estado, mercado e sociedade que, segundo a abordagem defendida por seu principal formulador, o então ministro da Administração Federal e Reforma do Estado, Bresser Pereira, poderia ser qualificado como a via mais segura para permitir a superação do "patrimonialismo".

Não deixa de ser significativo, como nota Brunet (20I7), que o documento de apresentação da reforma administrativa de FHC considere a reforma realizada em I967, no início do regime militar, a "primeira reforma gerencialista do Brasil", por ter rompido com o modelo burocrático herdado das reformas realizadas por Vargas, cuja "pulsão centralizadora" teria "perpetuado o patrimonialismo sob a forma do clientelismo e da cooptação". ${ }^{4}$ No entanto, ainda segundo Brunet, diversamente do que teria sido feito a partir da reforma de I967, a reforma de FHC pretendia investir intensivamente na formação de uma elite burocrática altamente profissionalizada. 
Assim é que a expectativa era a de que os vícios da modernização varguista, interpretada segundo a noção weberiana de patrimonialismo, tal como no amplamente influente diagnóstico formulado por Faoro (I989), poderiam ser corrigidos pelo gerencialismo. Nesses termos, o gerencialismo faria nascer uma nova concepção do racional-legal entre nós, o qual teria sido obstruído pela cultura patrimonialista que, segundo Faoro, estaria presente desde a formação do país, por influência do absolutismo português. E o diagnóstico era o de que essa cultura patrimonialista teria sido em alguma medida reiterada pela Constituição de I988 que, como pontua Brunet (20I7: 93), é vista pela coalizão reformista do governo de FHC como antagônica à modernização administrativa, "na medida em que teria irradiado para toda a administração indireta federal e também para os demais entes da federação um modelo baseado em controles excessivamente rígidos e burocráticos".

Ainda que seja uma questão em si mesma interessante - a de se pensar esse truque retórico, que faz com que o gerencialismo seja deslocado dos embates entre trabalhistas e conservadores na Inglaterra, cuja disputa se dava no terreno da reforma do Estado welfareano britânico, para pousar nos trópicos como categoria aliada do racional-legal -, não é esse o ponto que aqui nos interessa mais de perto. O que sim importa no momento é salientar que o gerencialismo entra no Brasil como uma doutrina que associa a modernização do Estado à introdução de um padrão de gestão orientado por critérios de eficiência e eficácia tomados de empréstimo do mercado. Por aí, também, é que ele será facilmente associado por seus críticos ao neoliberalismo. De fato, a reforma administrativa do Estado então proposta é percebida como parte de uma reforma mais ampla, que também inclui mudanças na legislação trabalhista, na presença do Judiciário nas relações de trabalho, além de várias medidas voltadas para a desregulamentação/flexibilização da economia. E a isso também se somava uma agenda de privatização de empresas estatais e de redefinição da divisão do trabalho entre Estado, mercado e sociedade. Por isso, não seria exagero afirmar que mais do que doutrina de uma reforma administrativa, o gerencialismo se confunde no Brasil com um esforço de profunda reforma da ordem social. ${ }^{5}$ No entanto, como esse movimento não encontra maior ressonância na sociedade, seguiu sendo um processo conduzido a partir de cima, por uma elite política reformista. Ainda assim, representou o principal esforço de modernização do Estado desde a redemocratização do país, produzindo impactos em diferentes áreas do serviço público.

$\mathrm{Na}$ área da educação, importa ressaltar que, em seu contexto original, o gerencialismo pode ser tomado como um ingrediente que se soma ao movimento reformista que vinha ocorrendo em boa parte dos países do Ocidente a partir do final da década de I960. Tal processo está relacionado, sobretudo, à complexificação do sistema educacional decorrente da massificação do ensino médio no contexto do pós-guerra. Assim é que, bem antes da emer- 
gência da doutrina que se convencionou chamar de gerencialismo, já estava em curso todo um esforço de construção de um campo da gestão escolar que, pode-se dizer, desloca a prevalência da sociologia da educação, e de sua métrica, associada ao estudo da relação entre educação e desigualdade social, como seria demonstrado por uma sociologia voltada para estudos da relação entre escolarização e estrutura social (Bourdieu \& Passeron, 20I4). Em seu lugar, entra em cena uma nova geração de autores, do campo da ciência da administração, da estatística, da psicologia, da economia e da ciência política, que se irão debruçar na formulação de novos desenhos de políticas educacionais, novas formas de gestão e novas formas de mensuração da aprendizagem.

De fato, a emergência da gestão escolar pode ser associada à aposta no poder da escola enquanto agência capaz de produzir resultados mesmo quando diante de contextos difíceis. Com isso, ganha força outro tipo de métrica, que valoriza o resultado do trabalho escolar, mensurado pelo desempenho acadêmico do aluno.

No caso brasileiro, diversamente do anglo-saxônico, talvez não seja exagero afirmar que a valorização da gestão escolar já nasce sob o impacto da influência do gerencialismo. Nesse sentido, a valorização da gestão escolar, de um lado, e o modelo gerencialista, de outro, ainda que sejam processos distintos, no Brasil eles se apresentam como fenômenos simbioticamente articulados, o que ajuda a explicar por que, não raro, a crítica à noção de gestão escolar se apresenta como uma crítica ao gerencialismo, e vice e versa. Fato é que tal simbiose passa a informar a imaginação reformista do sistema educacional no Brasil, para a qual não faltou, aliás, um forte impulso de instituições privadas, muitas delas ligadas ao sistema financeiro, que passaram a formular e a implementar programas de ação voltados para o fortalecimento da cultura de gestão nas escolas. Em seu já citado estudo sobre as políticas públicas educacionais, Cristina Dusi (20I7) apresenta um quadro descritivo bastante convincente quanto à convergência gerencialista no período, deixando evidente que os mais bem sucedidos Estados em termos educacionais entre meados dos anos I990 e 2014 se valeram de instrumentos tipicamente gerencialistas, tais como política de metas, sistemas de incentivos como premiação e bonificação salarial, e sistemas de monitoramento e avaliação em larga escala.

Esse reformismo animado pelo gerencialismo, porém, tem dado sinais de esgotamento. Dois tipos de desafios explicitam bem esse esgotamento. $\mathrm{O}$ primeiro tem a ver com a dificuldade em face da resistência à mudança de comportamento profissional, que costuma ser forte na área da educação. De fato, apesar dos avanços no esforço de qualificação e certificação profissional dos diretores, a onda reformista realizada pelos estados e municípios não transformou senão parcialmente a cultura profissional de tipo personalista que caracteriza a relação dos diretores com as escolas (Burgos \& Canegal, 20 I I), 
os quais, diga-se, ainda são, em boa parte das redes do país, indicados politicamente para o cargo. Entre os professores, o investimento de algumas redes na formação continuada, associado ao uso intensivo de mecanismos de monitoramento e avaliação, tem produzido resultados interessantes no sentido de alterar padrões de comportamento docente, aumentando sua responsabilidade com o resultado escolar. Mas mesmo nesses casos de sucesso relativo, sua sustentabilidade depende de que o modelo gerencialista se transforme em formas mais horizontais de gestão do trabalho escolar. ${ }^{6}$

O segundo desafio tem a ver com as dificuldades de se produzirem alterações mais consistentes no desempenho dos estudantes, em especial nos anos finais do ensino fundamental e no ensino médio. A questão da melhoria dos resultados escolares esbarra, entre outros fatores, na dificuldade de se conceberem escolas mais responsivas em relação aos seus alunos, com mais foco no estudante e em sua realidade, e maior abertura à sua participação, condições que, no mínimo, exigiriam muitas mudanças na proposta de se nortear a busca de resultados segundo a lógica das metas, incentivos e bonificação por resultados.

Do fato de esses desafios não terem sido vencidos, não se segue que não tenha havido nas últimas duas décadas um significativo avanço na organização do sistema educacional no país; indica, isso sim, que o modelo gerencialista parece não oferecer mais horizonte para o aprofundamento das reformas educacionais. Talvez a melhor evidência desse esgotamento tenha sido produzida pelo movimento de ocupação das escolas públicas de Ensino Médio, que ocorre em quase todos os estados da federação entre 2015 e 20I6, com especial força em São Paulo, Rio de Janeiro e Paraná. Protagonizado por estudantes secundaristas, boa parte deles de classes populares, esse movimento representa um inédito momento de luta estudantil em defesa de uma escola pública de qualidade e, sobretudo, de uma escola aberta à sua participação. Nesse sentido, questiona frontalmente o modelo tecnocrático que caracterizara a história recente de reformas educacionais. Com as ocupações, os estudantes passam a disputar com os professores e seus sindicatos, mas também com a direção da escola e as burocracias das secretarias de educação, a prerrogativa de definir o sentido da escola, reivindicando que sua voz seja ouvida e considerada. Os efeitos desse processo ainda não foram plenamente sentidos, mas é inegável que a força do movimento de ocupações coloca em xeque premissas e procedimentos que tinham se cristalizado como parte da cultura de gestão. De especial importância é o duro questionamento que os estudantes fazem da atuação dos diretores escolares, criticados, sobretudo, pela falta de transparência e de diálogo (Campos, Medeiros \& Ribeiro, 20I6; Camasmie, 20I8).

Uma segunda evidência que denota o esgotamento da simbiose entre o gerencialismo e a cultura de gestão veio do próprio governo federal. Logo 
após a deposição de Dilma Rousseff, o novo governo, presidido por Michel Temer (20I6-20I8), aproveita a divulgação do IDEB de 20I5, que indica uma estagnação nos resultados do Ensino Médio, para acusar o "atual modelo de Ensino Médio como uma tragédia".7 Forja-se em pouco tempo uma narrativa da "catástrofe", que desqualifica todo o esforço realizado pelos estados até então. Em seguida, como uma resposta a esse diagnóstico o governo apresenta, em forma de medida provisória, a chamada "reforma do Ensino Médio". Com isso, ataca frontalmente a aposta que vinha sendo feita até então, de se construir um novo modelo de gestão capaz de melhorar os resultados escolares. O foco da questão se desloca: o difícil avanço na melhoria do Ensino Médio não é mais encarado como um problema de gestão; é o modelo todo que está errado, e que precisa ser alterado. Em curtíssimo prazo, o Congresso Nacional aprova a medida provisória, convertendo-a na lei no I3.4I5/20I7. Sua tônica é a flexibilização do currículo, e não a melhoria da gestão escolar e muito menos a ampliação da participação estudantil. A tal ponto a nova lei ignora a acumulação anterior que, na verdade, oferece como novo horizonte para a gestão um cenário de caos administrativo. Afinal, como imaginar que as escolas públicas estaduais, muitas vezes já fragilizadas, conseguirão responder à necessidade de oferecer diferentes itinerários para seus alunos? Embora não se possa arriscar o que irá acontecer com a nova lei, não estando mesmo descartada uma espécie de desobediência civil em face dela, sua aprovação, feita sob um clima de urgência, é em si mesma um sintoma forte de que o consenso criado em torno da simbiose entre gerencialismo e cultura de gestão se desfez. Em seu lugar, o que se tem hoje é um quadro de muitas incertezas, que a emergência com relativa força do movimento/programa "Escola Sem Partido" não deixa de exprimir (Frigotto, 20I7).

A relação simbiótica entre gerencialismo e cultura de gestão foi, sem dúvida, um capítulo importante para a construção de um sistema educacional pautado pela ideia de eficácia, por isso, se a hipótese de que esse modelo se esgotou fizer sentido, será necessário estimular uma nova imaginação para pensar a reforma educacional, de modo a se seguir avançando na direção traçada por todo um arcabouço institucional que aponta a importância da educação para a democracia no país, tal como previsto na Constituição de I988 e no Estatuto da Criança e do Adolescente (I990), e estabelecido pela Lei de Diretrizes e Bases da Educação (I996) (Burgos, 20I4).

Para esse fim, pode ser muito bem-vinda a revisão de uma literatura que, há mais de uma década, tem explorado teoricamente o problema dos limites do gerencialismo e construído novos conceitos que, mais do que simplesmente romper com o modelo anterior, pretendem se afirmar como uma contribuição para a articulação entre a busca por eficiência na garantia dos direitos de aprendizagem dos estudantes e o papel da escola na formação da cultura democrática. Por essa via, a incursão nessa literatura também permi- 
te encontrar pontos de comunicação com o modelo de participação societal de que fala Paes de Paula (2005).

\section{TENDÊNCIAS DA LITERATURA PÓS-GERENCIALISTA}

A perspectiva adotada no livro Change Wars, organizado por Fullan e Hargreaves (2009), é a de que para uma mudança educacional acontecer é preciso, além da prescrição política, a participação ativa e o comprometimento daqueles que fazem parte das instituições de educação e estão mais próximos da realidade da sala de aula. Mas é no Second International Handbook of Educational Change (Hargreaves et al., 20Ioa), livro que reúne mais de 40 autores de diferentes partes do mundo, que essa linha de argumentação ganha maiores alcance e densidade. Em suas mais de mil páginas, o Handbook organiza um debate que, a nosso ver, sintetiza as mudanças pelas quais a imaginação reformista no campo da educação vem passando desde a primeira década do século XXI.

A partir de suas experiências como pesquisadores, profissionais da educação, consultores ou ainda implementadores de políticas públicas, os autores que participam dessa coletânea apresentam distintas possibilidades de mudança educacional, mas convergem em torno da aposta na iniciativa e criatividade individual dos profissionais da educação, bem como no investimento em sua formação. Não se trata apenas de uma questão tática, mas sim de uma compreensão de que a mudança não pode ser concebida a partir de cima, em abstrato, sendo necessário valorizar o contexto e a participação. O desafio focalizado por essa literatura, que estamos chamando de pós-gerencialista, é conciliar reforma educacional de larga escala com uma abordagem democrática que oriente o processo de mudança e valorize o envolvimento da base. O equilíbrio entre as perspectivas top-down e bottom-up, a ênfase no profissionalismo e na cooperação e a concepção de um novo tipo de liderança são dimensões dessa abordagem da reforma educacional, que busca reconciliar o reformismo com um ideal democrático de educação.

A aposta na participação da sociedade e dos "burocratas do nível de rua", marca da perspectiva pós-gerencialista, não dispensa formas de coordenação e avaliação que provaram ser importantes em outro momento. A crítica ao modelo burocrático do Welfare State, e a valorização de um modelo de eficiência baseado em critérios gerenciais, cede terreno a uma reflexão que procura valorizar a dimensão participativa no processo educacional. A ideia de eficiência, nesse cenário, já não pode estar referida apenas a resultados pontuais conferidos por avaliações externas que mensuram o aprendizado dos alunos, ignorando o contexto escolar e, de uma perspectiva mais ampla, a própria missão da instituição escolar em uma sociedade democrática. Hoje, a questão seria encontrar pontos de equilíbrio, que assegurem que processos de mudança não cancelem a responsabilidade e o compromisso com a escolarização, tampouco a criatividade e a 
valorização do contexto, o que pressupõe a participação dos diferentes segmentos que compõem a comunidade escolar.

Por outro lado, essa bibliografia se mostra muito preocupada em não perder de vista que, ainda que se abra mais espaço para a discricionariedade, processos de reforma educacional precisam ser conduzidos de modo sistêmico. Segundo Fullan (20I0: I 29), os sistemas escolares são conhecidos pela falta de coesão e pela fragmentação. Nessas condições, existiria muito espaço para inércia. Pressões positivas seriam então necessárias para mobilizar os profissionais e conduzir de forma sistêmica o processo de mudança educacional, mas sem perder de vista a necessidade de se levar a sério a agenda de estudos sobre formas complementares e mais participativas de responsabilização pelos resultados.

Apesar da valorização da mensuração do aprendizado como necessário para identificar se as escolas estão cumprindo ou não sua função educativa, a revisão da literatura pós-gerencialista sugere que avaliações externas são limitadas e em alguns casos podem esconder importantes questões contextuais. Certo descompasso entre os critérios de melhoria adotados pelo governo e a agenda de aprendizagem das escolas apontaria, conforme MacBeath (20I0), para a necessidade de combinar instrumentos de avaliação externa com formas de avaliação interna. Ao propor essa combinação, o autor questiona em que medida o ímpeto para a mudança se dá por sistemas de inspeção ou pressão. A autoavaliação é aqui valorizada como um processo contínuo de reflexão, que deve abarcar, além da performance do estudante em testes periódicos, o reconhecimento de que os aprendizados do aluno e do professor estão integralmente conectados ao aprendizado organizacional.

A abordagem gerencialista alterou o foco dos analistas para a questão do resultado escolar. Com isso, mais do que efeitos sociais, diminuição de desigualdade ou mobilidade social (questões caras à sociologia da educação), o eixo da pergunta passou a ser o do desempenho. Mesmo reconhecendo a relevância dessa abordagem, Teddlie (20I0) sustenta que a adoção descontextualizada de parâmetros de avaliação poderia desestimular processos de melhoria justamente nas escolas mais sensíveis. ${ }^{8}$

O que mais importa reter é que a busca por um novo balanceamento que permita a melhoria escolar nos dias atuais vai além da mera inversão entre as abordagens que priorizam soluções mais top-down ou bottom-up. E também a preocupação em conciliar métodos distintos de apreensão da realidade escolar e de formulação de soluções para seus problemas, articulando as experiências pessoais às evidências empíricas produzidas por sistemas de monitoramento e avaliação (Hargreaves et. al., 20 Iob). ${ }^{9}$

Outra linha de argumentação em defesa de uma concepção sistêmica que não seja inconciliável com maior abertura à participação é a formulada por Hopkins (2010). Para ele, existe uma tendência de as iniciativas de reforma 
em larga escala apresentarem um sucesso inicial seguido de estagnação e falta de compromisso com o projeto. É que o foco em habilidades-chave tende a produzir uma rápida melhora nos padrões de aprendizagem que, em médio prazo, não se mostram sustentáveis. Seria preciso uma abordagem sistêmica da melhoria escolar para garantir um avanço sustentável. Argumenta o autor que, a menos que as estratégias de reforma abordem o contexto do ensino e da aprendizagem, bem como a capacitação no nível escolar, as expectativas que as sociedades têm de melhoria para seus sistemas educacionais nunca serão realizadas. Segundo Hopkins (2010: 745), a reforma de larga escala usa a avaliação como espelho e tem uma visão de curto prazo. Com isso, não se altera nada mais profundamente no sistema. Diversamente, mudanças sistêmicas assumem que o que está em jogo é construir capacidades que possam impactar o desempenho de forma mais sustentável. Mais do que medir a melhoria apenas pela performance dos alunos a partir do vértice de uma rede educacional, Hopkins destaca a importância de se desenvolver a capacidade profissional no nível da escola como forma de assegurar mais sustentabilidade da melhoria dos resultados.

Como já se observou, o reconhecimento dos limites da utilização de dados para guiar os projetos de reforma tem colocado em cena a discussão sobre a importância da experiência cotidiana dos profissionais da educação para promoção da melhoria escolar. Disso se segue a valorização da discricionariedade e da criatividade (pontos centrais nesse novo equilíbrio entre abordagens verticais e horizontais de reforma) que, por seu turno, passa pela aposta no profissionalismo e na cooperação, com o que se pretende superar a antinomia entre políticas top-down e políticas bottom-up. Boa evidência dessa tendência aparece no trabalho de Joan Talbert (20I0: 560), que acusa a ênfase nos ganhos de curto prazo e nos resultados dos testes de impor um ritmo de mudança que mina o desenvolvimento de comunidades profissionais de aprendizado. A construção de uma comunidade profissional, como caracteriza a autora, não se dá meramente a partir de trabalho colaborativo entre os professores. Segundo Talbert, os sistemas centralizados diluem a responsabilidade coletiva já que a preocupação é com a conformidade e não com o efeito da ação do profissional. Por outro lado, o desenvolvimento da responsabilidade mútua dos professores se daria a partir da valorização da categoria profissional, bem como de sua articulação com a comunidade. Essa aposta no profissionalismo e na cooperação remete à valorização de uma perspectiva mais em rede do que hierárquica, bem como à construção de capacidade e responsabilidade mais do que de controle. ${ }^{\circ}$

Na mesma linha, Hargreaves (2009) observa que cada vez mais o que tem sustentado mudanças na área da educação não são intervenções e políticas governamentais, mas sim pessoas trabalhando juntas como uma equipe em torno de propósitos comuns e objetivos claros que tenham um sentido 
real para elas. O desafio atual para os projetos de reforma seria fazer com que diferentes pessoas trabalhem cooperativa e efetivamente por uma causa comum. A aposta do autor é a de que a difusão de um padrão de mudanças poderia se dar a partir da ideia de profissionalismo. Uma reforma educacional de sucesso dependeria de profissionais altamente qualificados que dispusessem de uma representação profissional eficaz e propositiva e que participassem de uma comunidade de aprendizagem dedicada a melhorar no longo prazo o aprendizado dos alunos. Hargreaves fala sobre o desenvolvimento de um senso de responsabilidade profissional, e um compromisso ético com o ensino, que poderia viabilizar a construção da melhoria a partir da base ainda que orientada pelo topo. A ênfase sobre a responsabilidade profissional, em vez da vigilância constante, preservaria, segundo ele, a criatividade e a possibilidade de customização em face de diferentes realidades.

Deve-se sublinhar que tal proposição evidencia uma diferença importante dessa perspectiva em relação à abordagem gerencialista. A ideia agora não é mais a da criação e recrutamento de uma elite bem treinada apta a gerir de forma padronizada o sistema escolar, mas sim o desenvolvimento da competência associada à formação de redes de profissionais. Como defende Linda Darling-Hammond (2009), não há políticas capazes de melhorar as escolas se os professores não tiverem os conhecimentos e habilidades necessários. Segundo ela, a lição de investir em professores foi aprendida pelas nações no topo dos rankings educacionais internacionais, que costumam preparar de maneira extensiva seus docentes - por meio de longa formação que possa criar uma ética profissional e intelectual - e pagar-lhes bons salários em relação às profissões concorrentes. Nessa perspectiva, os formuladores de políticas que desejem reformar o sistema para uma melhor performance devem investir em uma forte preparação inicial e no desenvolvimento contínuo dos profissionais, tendo como base o comprometimento com os alunos e com o conhecimento necessário para a prática pedagógica. Apesar de reconhecer que a padronização traz alguma eficiência, Darling-Hammond afirma que estas "regulamentações sem rosto" acabam se tornando o bode expiatório do fracasso escolar, já que ninguém no sistema assume a responsabilidade pelos seus efeitos sobre os alunos, ao passo que o incremento do profissionalismo, por sua vez, poderia promover uma melhora contínua da prática ao substituir a ideia de conformidade pela de responsabilidade. Afinal, o trabalho docente é muito complexo para ser prescrito de longe; por isso, o controle não deve vir de cima, mas, sobretudo, dos mecanismos de incentivo e sanção decorrentes da responsabilidade em face dos pares e da reputação profissional.

O profissionalismo, portanto, melhoraria a prática e aumentaria a responsabilização ao criar formas de garantir a competência e o comprometimento de cada um com suas obrigações. É importante esclarecer que essa abordagem não propõe um abandono dos mecanismos de gestão e supervisão 
da escola, e sim o fortalecimento da capacidade de regulação pelos próprios profissionais. Trata-se de um deslocamento, portanto, da configuração na qual a burocracia estatal chama para si a tarefa de planejar e implementar políticas educacionais, cabendo aos sindicatos dos profissionais da educação a tarefa de tentar impor limites ao que considera atentar contra os interesses da categoria que representa. Nesse tipo de arranjo, a dimensão da responsabilidade propriamente profissional costuma ser deixada em segundo plano em favor de conflitos sindicais que, frequentemente, acabam capturados por uma lógica corporativista, nem sempre compatível com o objetivo de melhorar a capacidade da escola de ensinar e de educar.

Em contraste com esse modelo centralizado de responsabilização que, em geral, tem como contraface os sindicatos, essa nova concepção aponta para a construção de uma comunidade profissional, na qual todos trabalham juntos para melhorar o ensino e a aprendizagem. Em síntese, pode-se afirmar que enquanto o modelo burocrático dilui a responsabilidade individual em favor da ideia de conformidade, e o gerencialismo valoriza o protagonismo de uma elite profissionalmente bem treinada e apta a gerir os processos de reforma, o pós-gerencialismo propõe o desenvolvimento de uma cultura profissional lastreada em uma ética da responsabilidade mútua em relação à performance dos alunos e ao desenvolvimento da comunidade. Nesse novo cenário, os sindicatos de modo algum perderiam sua importância, mas com certeza teriam seu papel redimensionado, assumindo-se mais claramente como porta-vozes de uma categoria profissional, cujos interesses não necessariamente coincidem com os dos demais segmentos escolares.

A emergência do tema do profissionalismo, aí incluída a ênfase na cooperação profissional, revela a valorização das formas coletivas de organização em torno do mundo da escola - sobretudo daquelas comprometidas com uma melhoria sustentável. ${ }^{\text {II }}$ Para a abordagem pós-gerencialista, a cooperação e a valorização de uma perspectiva em rede são importantes para a inovação. A prioridade passa a ser a ligação e a comunicação entre os profissionais, bem como a valorização do controle a partir de uma ética profissional, e não mais a conformidade aos desígnios burocráticos ou à vontade exclusiva de uma elite modernizadora.

Outra marca importante dessa literatura é a de que a aposta no profissionalismo e na cooperação pressupõe a ressignificação da ideia de liderança como figura-chave a articular as diferentes dimensões do processo de reforma educacional. De fato, nota-se uma convergência de diferentes autores em torno de uma concepção ampliada da ideia de liderança: um sistema de lideranças que aumente a responsabilidade coletiva, mais do que um líder como fiador de uma vontade oriunda do vértice. Em contraste com a ética competitiva inerente ao gerencialismo, agora a liderança deve estar atenta ao contexto e engajar-se em uma perspectiva sistêmica, compreendendo a interde- 
pendência entre as esferas educacionais. Além do comprometimento com o sucesso do estudante e com o desenvolvimento da escola, nessa nova abordagem compreende-se que a melhoria contínua das escolas só é possível com o avanço de todo o sistema. Para essa concepção, portanto, a liderança deve ser capaz de assumir um comprometimento moral em uma escala mais larga, sem descuidar da relação com a vida local e a comunidade escolar.

Bill Mulford (2010), entre outros pesquisadores, vem tentando construir uma passagem do modelo gerencialista de liderança educacional para uma nova concepção mais ligada à ideia de rede e de comunidade de aprendizagem. O autor opõe um modelo mais vertical a outro que encara o diretor como articulador e construtor de comunidades, defendendo que abordagens para a melhoria escolar devem ser construídas localmente. A liderança, nessa perspectiva, precisa compreender as necessidades locais ainda que tenha em mente a conformidade com ordens externas. O líder, portanto, tem que articular as ideias de aprendizado em rede com políticas centralizadas de reforma. "A liderança educacional bem-sucedida precisa ser capaz de ver e agir sobre o todo, bem como sobre os elementos individuais, e sobre as relações entre eles ao longo do tempo" (Mulford, 20I0: I99). Exerce, portanto, um importante papel de mediação. Com isso, desloca-se a ideia de um gestor detentor de um saber técnico, em favor de uma liderança que, além de domínio técnico, tem seu papel coletivamente legitimado a partir de interações que se dão no contexto local. Nesse sentido, seu compromisso não é apenas técnico, envolve também uma dimensão política. Moralmente comprometido com o seu contexto, esse líder é quem irá adaptar as estratégias de mudança para a realidade particular de sua escola.

Decisiva de um modo geral, a atuação dessa liderança atenta às questões locais seria ainda mais fundamental em estratégias de melhoria em escolas com dificuldades crônicas - especialmente aquelas em contextos desafiadores. Após rever a literatura sobre melhoria de escolas desse tipo, Alma Harris (20I0), identifica a tendência entre os autores de valorizar um perfil de liderança que precisa incorporar em sua atuação uma abordagem mais sociológica e antropológica do que estritamente técnica, e que deve se afirmar como agente capaz de equilibrar prescrição e discricionariedade, animando os profissionais em torno da ideia de cooperação.

É esse o espírito de uma literatura que, sobretudo no contexto anglo-saxônico, vem buscando reconciliar o projeto de reforma do sistema educacional com critérios afins à construção de sociedades democráticas. Talvez se pudesse dizer que o equivalente desse esforço em contextos como o da França pode ser encontrado em referências como Touraine (2003) e Dubet (2008), entre tantos outros, quando buscam saídas para o que muitas vezes tem sido denominado crise da escola republicana. E é interessante que na França, ainda que com muitas variantes, esse debate siga sendo fortemente dominado pela sociologia das instituições, ao passo que no contexto anglo-saxônico o diálogo com o campo 
da ciência da administração seja mais intenso. Isso não deixa de colocar luz no fato de que para este último contexto a dimensão do público é menos dominada pelo Estado e, por isso mesmo, um campo mais aberto a mudanças e inovações; bem como mais poroso à lógica dos interesses.

Para a literatura pós-gerencialista, reconectar a escola com a democracia pressupõe uma espécie de volta a princípios abandonados nesse percurso de mais de três décadas, quando se partiu em busca de um modelo administrativo capaz de conciliar tantas expectativas contraditórias em face do sistema escolar; uma volta aos fundamentos que, para boa parte desses autores, remete à tradição deweyana, que afinal tem a escola como uma instituição umbilicalmente vinculada à construção de uma sociedade democrática, que não pode se render às razões de um Estado tecnocrático e muito menos a uma ética mercantil que aposta na competição como vetor capaz de produzir eficiência e eficácia. Uma volta a velhos ideais, que fariam da escola uma das agências modernas mais importantes para a democracia, fonte de igualdade, autonomia, liberdade, solidariedade (fraternidade), cooperação e empatia. ${ }^{\text {I2 }}$ Uma volta aos princípios da escola democrática que, como adverte Hargreaves (2009), deveria se dar sem prejuízo da retomada dos aspectos considerados preciosos dos diferentes períodos da reforma educacional, tais como a aposta em um ambiente propício à inovação, a valorização da definição de diretrizes amplamente divulgadas e dos avanços técnicos das avaliações externas, a busca de equidade, e o uso de dados e evidências empíricas para informar gestores e professores em suas intervenções.

\section{CONSIDERAÇÕES FINAIS}

Enquanto momento de inovação da organização do Estado, o gerencialismo, com todas as suas tendências e variações nacionais, pode ser considerado um divisor de águas na reflexão a respeito da administração pública. Posto que se compromete com a qualidade dos serviços públicos, poderia, com justiça, ser encarado como uma forma de dar continuidade às promessas do Welfare State, como pretendeu o New Labour britânico, afirmando-se como uma alternativa "pós-burocrática" e mais eficiente de gestão de serviços públicos (Hall \& Gunter, 20I5). O problema é que essa marcação passa por cima do fato de que a onda gerencialista acaba cancelando não tanto algumas das principais promessas do Welfare, mas sim as da democracia em seu sentido mais pleno. Por isso, talvez o principal problema com o gerencialismo seja justamente o fato de ele responder de modo mais imediato às críticas de viés mais conservador feitas ao Welfare State, ignorando ou deixando em plano secundário as críticas que vinham sendo formuladas por segmentos mais progressistas e que, mais do que da ineficiência do Estado burocrático, reclamavam de sua falta de transparência e, sobretudo, de seu excessivo tecnocratismo e baixa abertura à participação dos cidadãos. 
Por outro lado, é verdade que o papel hegemônico que o gerencialismo assumiu em muitos contextos nacionais, com destaque para o Brasil, também reflete um vazio de alternativas ao tema da gestão, que o modelo societal não foi capaz de suprir. Esse quadro foi ainda mais comprometido pelo fato de que muitas vezes os críticos limitavam-se a acusar o gerencialismo de ser uma extensão do neoliberalismo, sem reconhecer a validade dos problemas que aquela matriz de reforma pretendia resolver no terreno da administração pública. ${ }^{\mathrm{I} 3}$ Daí a importância de recuperar alguns dos pontos fundamentais das críticas progressistas ao Welfare sem perder de vista a importância da dimensão da gestão. Acreditamos que seja essa a melhor forma de ler a literatura que aqui chamamos de pós-gerencialista, a qual, sem deixar de reconhecer a importância do gerencialismo, procura confrontá-lo com uma agenda reformista que recupera elos perdidos da crítica democrática ao Welfare.

De modo mais específico, este artigo parte da premissa de que uma boa maneira de estimular o debate em torno dessa agenda no Brasil é a interpelação de seu sistema educacional a partir das três vertentes que procuramos valorizar na leitura que fizemos da bibliografia pós-gerencialista, a saber: a busca de novas articulações entre os modelos top-down e bottom-up, a valorização da profissionalização e de formas de cooperação profissional, e a reflexão sobre como formas inovadoras de liderança podem ser conciliadas com aspectos institucionais característicos de cada país.

Nossa aposta é a de que a afirmação dessa nova imaginação muito ganhará caso se desenvolva um diálogo mais intenso entre os campos da ciência política e da ciência da administração, tradicionalmente dedicados ao estudo das políticas públicas, e uma sociologia da educação voltada para a escola, mas preocupada com os nexos entre a dimensão institucional e teorias da ação social, tal como vem propondo há algum tempo François Dubet (I994; Dubet \& Martuccelli, I996). Acreditamos que essa articulação seja fundamental, justamente por favorecer uma abordagem menos ingênua da administração (e da administração escolar em especial), a qual, como nos lembra Guerreiro Ramos (I98I) em seu estudo clássico sobre o assunto, é sempre devedora de uma ciência social que, por seu turno, nem sempre é reflexiva em face de suas repercussões sobre as teorias das organizações.

Com base na argumentação proposta neste artigo, pode-se afirmar que a valorização das esferas de participação de professores e de estudantes na construção do espaço escolar, e a sua relação com a melhoria da aprendizagem, passa fundamentalmente pela reflexão sobre o desenho de políticas educacionais voltadas para a mudança, que incluam, entre outros, aspectos tais como a ênfase na formação docente continuada comprometida com os resultados escolares; a aposta no desenvolvimento de uma nova vida associativa profissional, capaz de estimular o surgimento de comunidades de aprendizagem entre gestores e entre docentes; e a organização de um sistema de lide- 
ranças que estimule entre nós novas formas de responsabilidade individual pelo trabalho coletivo na educação.

De uma perspectiva normativa, essas são apenas algumas das dimensões fundamentais que a literatura pós-gerencialista aporta à constituição de uma nova imaginação para as políticas educacionais no Brasil e que, muito além do estéril debate animado pelo chamado "escola sem partido", precisará conformar um modelo de gestão mais compatível com os desafios culturais e institucionais que precisarão ser enfrentados para a realização das necessárias mudanças em um sistema educacional que ainda precisa avançar muito na afirmação do direito à aprendizagem, bem como na promessa de formar sujeitos dotados de autonomia.

Como procuramos sustentar neste artigo, essa nova imaginação guarda afinidade eletiva com uma sociologia da educação que vem se empenhando em ultrapassar os marcos do dilema entre uma sociologia da reprodução (amplamente influenciada por Bourdieu), cética em relação ao poder transformador da escola, e o chamado "otimismo pedagógico", que parece atribuir poderes quase mágicos à força da gestão (López, 2005). Desse ponto de vista, pode-se afirmar que a abordagem pós-gerencialista aponta para uma tendência de maior sociologização da gestão escolar, à medida mesmo que as práticas e as experiências passam a contar mais como dimensões constitutivas da vida institucional. E essa tendência não deixa de encontrar solo fértil na vida educacional do Brasil, justamente pelo tipo de conflito que aqui se estabeleceu entre o gerencialismo, de um lado, e o modelo participativo, de outro.

Uma boa evidência disso aparece quando se considera especificamente a questão da eficácia escolar, que inclui o uso de sistemas de avaliação externa e instrumentos de gestão voltados para a responsabilização da escola e de seus profissionais pelos resultados dos alunos. Apesar de muito cara ao modelo gerencialista, essa agenda de modo algum se confunde com ele, e é particularmente interessante observar como tem sido costumizada no país, adequando-se às diversas realidades das redes, escolas e seus diferentes contextos. Ao tratar desse tema, Passone (20I9), que realiza uma análise da produção bibliográfica brasileira sobre o assunto na última década, constata a valorização do enfoque na realidade local das escolas, verificando um acúmulo crescente de conhecimento sobre esses contextos. Com base nessa tendência, o autor identifica a afirmação de uma abordagem mais participativa para fazer frente aos obstáculos que precisam ser superados para a melhoria da eficácia escolar.

No entanto, a tirar pelo que vem se passando no país, ao menos desde 2016 e, sobretudo, a partir do governo Bolsonaro, há sérios riscos de que nos desviemos desse caminho, reduzindo-se a escola não aos desígnios tecnocráticos típicos ao gerencialismo, e com o qual se pretendeu romper com o que se identificava como o caráter patrimonialista do Estado e de seus serviços 
públicos, mas agora à lógica estrita da racionalidade instrumental cara ao mercado. É curioso constatar que, mais do que nunca, faz sentido para nós a advertência feita por Guerreiro Ramos (I98I), no início da década de I980, quando acusava uma certa "ciência social e administrativa" de nada mais do que "uma ideologia legitimadora da sociedade centrada no mercado". Nossa proposição é a de que a abordagem pós-gerencialista pode ser lida, portanto, como um convite a uma reflexão mais profunda sobre o papel do Estado e do serviço público, que tem na área da educação talvez a sua mais fundamental dimensão.

Recebido 7/3/20I9 | Revisto I8/8/20I9 | Aprovado 28/8/20I9

Marcelo Burgos é doutor em sociologia pelo Iuperj e professor e pesquisador do Departamento de Ciências Sociais da PUC-Rio. Tem realizado pesquisas nas áreas da sociologia urbana, sociologia do direito e sociologia da educação. Entre outros trabalhos, publicou os livros A utopia da comunidade. Rio das Pedras, uma favela carioca (2002), Corpo e alma da magistratura brasileira (I997), Judicialização da política e das relações sociais no Brasil (I999). De modo mais específico, na área da sociologia da educação publicou, além de artigos, os livros A escola e a favela (2009), e A escola e o mundo do aluno (2015).

Caíque Bellato é doutorando em ciências sociais pelo PPGCIS/PUC-Rio e mestre em ciências sociais pela mesma instituição. Tem realizado pesquisas nas áreas da sociologia da educação e da sociologia da religião. Pesquisador do CAEd/UFJF, entre 2015 e 2018. 


\section{NOTAS}

I Assim, concordando com Abrucio (I997: 28), antes de ser um paradigma, o gerencialismo se caracteriza por "um pluralismo organizacional sob bases pós-burocráticas vinculadas aos padrões históricos (institucionais e culturais) de cada nação".

2 Como observa Gabriela Lotta (2015: 43), adotando a caracterização de Michael Lipsky, os "burocratas de rua são funcionários que trabalham diretamente no contato com os usuários dos serviços públicos, tais como policiais, professores e profissionais da saúde". Por isso mesmo, conclui a autora, estão "no foco da controvérsia política, tendo em vista que são pressionados pelas demandas de serviços para aumentarem a efetividade e a responsividade, ao mesmo tempo em que são pressionados pelos cidadãos para aumentarem a eficiência e a eficácia".

3 Antes de nós, João Pedro Schmidt (2007) utiliza a noção de pós-gerencialismo para pensar mudanças no campo da administração pública no Brasil a partir dos anos 2000, em especial a partir do primeiro governo Lula. Sua caracterização converge com a nossa em vários aspectos, mas é claro que Schmidt não teria como se apropriar da massa crítica gerada por uma bibliografia internacional produzida justamente no contexto em que ele esboçava sua caracterização do que entendia ser o "pós-neoliberalismo" e o "pós-gerencialismo".

4 Como nota Brunet (2017: 92), "Os paradigmas modernizadores que o Plano Diretor [da reforma administrativa intentada por FHC] enaltece na reforma administrativa de I967 são, principalmente, a descentralização de funções para a administração indireta e a flexibilização dos critérios de seleção de pessoal e de aferição de metas de desempenho no âmbito daqueles entes administrativos".

5 Foi também, como bem assinala Brunet (20I7), um suporte para as reformas macroeconômicas orientadas para a implantação de uma política de estabilidade monetária e justificadas pela necessidade de tornar o país competitivo em face das novas exigências da globalização.

6 Uma boa evidência desse tipo de política voltada para a transformação da cultura docente é a experiência do Pro- 
grama de Alfabetização na Idade Certa, desenvolvida no Ceará. Para conhecer esse programa e seu impacto no comportamento docente, ver Rossi (2010).

7 "Não vamos fazer de conta que essa tragédia não existe", declarou, à época, o recém-empossado ministro da Educação, Eduardo Mendonça Filho. Disponível em <http://g I. globo.com/educacao/noticia/ideb-no-ensino-medio-ficaabaixo-da-meta-nas-escolas-do-brasil.ghtml>. Acesso em I2 set. 2017.

8 Alma Harris (20I0) afirma que a imposição de modelos padronizados de intervenção escolar pode ser contraproducente em escolas localizadas em contextos vulneráveis e que um programa de melhoria escolar contextualizado precisaria de flexibilidade e diversidade para atender às necessidades dos alunos.

9 Para esses autores, seria preciso respeitar o valor dos dados em oposição à intuição subjetiva, mas desde que se reconheça que, às vezes, a evidência é insuficiente e que para o avanço do sistema é necessário dar atenção à experiência daqueles profissionais envolvidos diretamente com o contexto escolar (Hargreaves et al., 2orob: xvii).

Io Para Talbert (20I0:559), as comunidades profissionais de aprendizado vibrantes, que continuamente aprendem a melhorar o desempenho dos alunos, são conectadas em rede com colegas de universidades locais e redes profissionais dentro e fora do sistema escolar. Elas desenvolvem seus conhecimentos e habilidades pela experimentação, bem como por meio de intercâmbios. Tais comunidades criam e compartilham ferramentas e materiais eficazes em suas salas de aula, circulam e discutem leituras e usam protocolos para aprender juntas.

I I Louise Stoll (2010), por exemplo, defende o desenvolvimento de capacidades para mudanças sistêmicas que são geradas por meio de comunidades de aprendizagem conectadas. Contra a ideia de que a mudança vem de cima, Stoll aponta a inovação como resultado da comunidade de aprendizagem e a sustentabilidade da mudança sistêmica como produto de um processo contínuo de aprendizado dos indivíduos.

I2 O livro de John Dewey (I979) Democracia e educação, originalmente publicado em I9ı6, segue sendo uma referência 
fundamental ao debate político do campo da educação, sobretudo para os países de língua inglesa. Para uma boa evidência desse tipo de posição deweyana no debate contemporâneo, ver Apple \& Beane (200I). Para uma discussão sobre a importância da cooperação e da empatia para as sociedades contemporâneas, ver Sennet (20I2).

I3 Com boa dose de razão, o ex-ministro Bresser Pereira (20I0) sustenta que as reformas gerencialistas foram, no Brasil, a melhor defesa do Welfare State, uma vez que garantiam, no seu entendimento, a "eficiência do consumo coletivo". Por isso, para ele, seria um equívoco vincular a reforma gerencial implementada no país em I995 com o neoliberalismo: "podemos pensar na reforma gerencial não como a consequência, mas como o instrumento do Estado do bem-estar social e como fator fundamental de sua legitimação" (Bresser Pereira, 20I0:I16).

\section{REFERÊNCIAS BIBLIOGRÁFICAS}

Abrucio, Fernando. (I997). O impacto do modelo gerencial na Administração Pública: um breve estudo sobre a experiência internacional recente. Cadernos ENAP [online], Io. Disponível em <http://antigo.enap.gov.br/downloads/ ec43ea4fAbrciocad\%20I0.pdf>. Acesso em 8 set. 2017.

Apple, Michael \& Beane, James. (200I). Escolas democráticas. São Paulo: Editora Cortez.

Bourdieu, Pierre \& Passeron , J.C. (20I4) [1964]. Os herdeiros: os estudantes e a cultura. Florianópolis: Editora da UFSC.

Bresser Pereira, L.C. (20Io). Democracia, Estado social e reforma gerencial. Revista de Administração de Empresas, 50/I, p. II2-II6. Disponível em <http://www.scielo.br/pdf/ rae/v50ni/aogv5oni.pdf>. Acesso em I6 set. 2017.

Brunet, Emiliano. (2017). Reforma do Estado no governo Fernando Henrique Cardoso (1995-2002): Ideologia reformista, economicismo e direito em uma época de mudanças. Rio de Janeiro: Editora Lumen Juris.

Burgos, Marcelo (coord.). (20I4). A escola e o mundo do aluno. Rio de Janeiro: Garamond.

Burgos, M. B. \& Canegal, A. C. (20II). Diretores escolares em um contexto de reforma da educação. Revista Pesquisa e Debate em Educação, I/, p. 2I-43. 
Camasmie, Mariana Junqueira. (2018). O movimento de ocupação das escolas e as novas formas de fruição da juventude escolarizada nas classes populares do Brasil. Dissertação de Mestrado. PPGCS/Pontifícia Universidade Católica do Rio de Janeiro.

Campos, Antônia; Medeiros, Jonas \& Ribeiro, Márcio M. (20I6). Escolas de luta. São Paulo: Veneta.

Darling-Hammond, Linda. (2009). Teaching and the change wars: the professionalism hypothesis. In: Hargreaves, Andy \& Fullan, Michael (eds.). Change wars. Bloomington: Solution Tree, p. 45-68.

Dewey, John. (1979). Democracia e educação. São Paulo: Companhia Editora Nacional.

Dubet, François. (2008). O que é uma escola justa?. São Paulo: Editora Cortez.

Dubet, François. (1994). Sociologie de l'expérience. Paris: Editions Du Seuil.

Dubet, François \& Martuccelli, Danilo. (1996). À L'école. Sociologie de l'expérience scolaire. Paris: Editions Du Seuil.

Dusi, Cristina Sayuri Cortes Ouchi. (2017). Os efeitos da gestão para resultados na educação: uma análise das políticas públicas educacionais de sete estados brasileiros. Tese de Doutorado. PPGCS/Pontifícia Universidade Católica do Rio de Janeiro.

Faoro, Raymundo. (I989). Os donos do poder: formação do patronato político brasileiro. Rio de Janeiro: Globo.

Frigotto, Gaudêncio (org.). (2017). Escola "sem" partido: esfinge que ameaça a educação e a sociedade brasileira. Rio de Janeiro: Uerj/LPP.

Fullan, Michael. (20I0). Positive pressure. In: Hargreaves, Andy et al. (eds.). Second International Handbook of Educational Change. [s.l.]: Springer Science + Business Media (Springer International Handbooks of Education, 23), p. I I9-I30.

Fullan, Michael \& Hargreaves, Andy (eds.). (2009). Change wars. Bloomington: Hawker Brownlow Education.

Hall, David \& Gunter, Helen M. (20I5). A nova gestão pública na Inglaterra: a permanente instabilidade da reforma neoliberal. Educação \& Sociedade, Campinas, 36/132, p. 743758.

Hargreaves, Andy. (2009). The fourth way of change: towards an age of inspiration and sustainability. In: Har- 
greaves, Andy \& Fullan, Michael (eds.). Change wars. Bloomington: Hawker Brownlow Education, p.II-44.

Hargreaves, Andy et al. (eds.). (2010a). Second International Handbook of Educational Change. [s.l.]: Springer Science + Business Media (Springer International Handbooks of Education, 23)

Hargreaves, Andy et al. (20Iob). Introduction: Ten years of change. In: Hargreaves, Andy et al. (eds.). Second International Handbook of Educational Change. [s.l.]: Springer Science + Business Media (Springer International Handbooks of Education, 23), p. xi-xxi.

Harris, Alma. (2010). Improving schools in challenging contexts. In: Hargreaves, Andy et al. (eds.). Second International Handbook of Educational Change. [s.l.]: Springer Science + Business Media (Springer International Handbooks of Education, 23), p. 693-706.

Hopkins, David. (2010). Every school a great school - realising the potential of system leadership. In: Hargreaves, Andy et al. (eds.). Second International Handbook of Educational Change. [s.1.]: Springer Science + Business Media (Springer International Handbooks of Education, 23), p. 74I-764.

López, Néstor. (2005). Equidad educativa Y desigualdad social. Desafíos a la educación en el nuevo escenario latinoamericano. Buenos Aires: Instituto Internacional de Planeamiento de la Educación/Unesco.

Lotta, Gabriela Spanghero. (20I5). Burocracia e implementação de políticas de saúde: os agentes comunitários na Estratégia Saúde da Família. Rio de Janeiro: Fiocruz.

MacBeath, John. (20I0). Self-evaluation for school improvement. In: Hargreaves, Andy et al. (eds.). Second International Handbook of Educational Change. [s.l.]: Springer Science + Business Media (Springer International Handbooks of Education, 23), p. 90I-9I2.

Mulford, Bill. (2010). Recent developments in the field of educational leadership: the challenge of complexity. In: Hargreaves, Andy et al. (eds.). Second International Handbook of Educational Change. [s.l.]: Springer Science + Business Media (Springer International Handbooks of Education, 23), p. $187-208$. 
Paes de Paula, Ana Paula. (2005). A administração pública brasileira entre o gerencialismo e a gestão social. Revista de Administração de Empresas, 45/r, p. 36-49. Disponível em <https://rae.fgv.br/sites/rae.fgv.br/files/artigos/IO.I590_ So034-75902005000100005.pdf>. Acesso em 25 set. 2017.

Passone, Eric Ferdinando Kanai. (2019). Gestão escolar e democracia: o que nos ensinam os estudos de eficácia escolar. Laplage em Revista. Sorocaba, 5/2, p. I42-I56.

Ramos, Alberto Guerreiro. (I98I). A nova ciência das organizações. Uma reconceituação da riqueza das nações. Rio de Janeiro: FGV.

Rossi, Jocelaine Regina Duarte. (20I0). Entre o estável e o fortuito: a formação continuada em serviço e as rotinas pedagógicas em alfabetização. Tese de Doutorado. PPGEB/Universidade Federal do Ceará.

Schmidt, João Pedro. (2007). Gestão de políticas públicas: elementos de um modelo pós-burocrático e pós-gerencialista. In: Direitos sociais e políticas públicas: desafios contemporâneos, 7. Santa Cruz do Sul: Editora Edunisc.

Sennet, Richard. (20I2). Juntos: os rituais, os prazeres e a política da cooperação. Rio de Janeiro/São Paulo: Record.

Stoll, Louise. (2010). Connecting learning communities: capacity building for systemic change. In: Hargreaves, Andy et al. (eds.). Second International Handbook of Educational Change. [s.l.]: Springer Science + Business Media (Springer International Handbooks of Education, 23), p. 469-484. Talbert, Joan E. (20I0). Professional learning communities at the crossroads: how systems hinder or engender change. In: Hargreaves, Andy et al. (eds.). Second International Handbook of Educational Change. [s.l.]: Springer Science + Business Media (Springer International Handbooks of Education, 23), p. 555-572.

Teddlie, Charles. (2010). The legacy of the school effectiveness research tradition. In: Hargreaves, Andy et al. (eds.). Second International Handbook of Educational Change. [s.l.]: Springer Science + Business Media (Springer International Handbooks of Education, 23), p. 523-554.

Touraine, Alain. (2003). Poderemos viver juntos? Iguais e diferentes. 2 ed. Petrópolis: Vozes. 
Palavras-chave

Educação e democracia; reforma educacional; gerencialismo; gestão escolar
Keywords

Education and democracy; educational reform; managerialism; school management.

\section{GERENCIALISMO E PÓS-GERENCIALISMO: EM BUSCA DE UMA NOVA IMAGINAÇÃO PARA AS POLÍTICAS EDUCACIONAIS NO BRASIL}

\section{Resumo}

Após cerca de duas décadas de predomínio da perspectiva gerencialista como referência para o reformismo no sistema educacional brasileiro, verifica-se uma crise de imaginação, a qual não deixa de produzir um vazio que ajuda a explicar o atual protagonismo de questões relacionadas à moralidade e a clivagens ideológicas no debate sobre educação. E isso em um país que ainda encontra sérios problemas para assegurar o direito básico de aprendizagem. Na literatura internacional, a crise do gerencialismo já se encontra fartamente mapeada, animando o desenvolvimento de novos pressupostos e conceitos que procuram incorporar suas principais virtudes e avançar em relação a seus limites. Denominamos essa literatura "pós-gerencialista", sustentando que sua leitura pode ser de grande valia para fomentar a inovação nas políticas educacionais, tendo em vista a necessidade de aprofundarmos as promessas da Constituição de I 988 , que faz da escola uma âncora fundamental para a democracia brasileira.

\section{MANAGERIALISM AND POST-MANAGERIALISM: IN SEARCH OF A NEW IMAGINATION FOR EDUCATIONAL POLICIES IN BRAZIL}

\section{Abstract}

After approximately two decades in which the managerial perspective has predominated as the main framework for reformism in the Brazilian educational system, a crisis of imagination has emerged, generating a void that helps explain the current prominence of issues relating to morality and the ideological schisms now found within the education debate. Moreover, this situation has occurred in a country that still encounters serious problems ensuring the basic right to education. In the international literature, the crisis in managerialism has already been densely mapped, encouraging the development of new premises and concepts that seek to incorporate its main virtues and advance beyond its limitations. We refer to this literature as 'post-managerialist,' arguing that its reading can be valuable to fostering innovation in educational policies, recognizing the need to deepen the promises of the I988 Constitution, which makes schooling a basic foundation of Brazilian democracy. 